\title{
STUDY ON PINHOLE LEAKS IN GAS PIPELINES: CFD SIMULATION AND ITS VALIDATION
}

\author{
BURAK AYYILDIZ1 ${ }^{1}$ MUHAMMAD AZIZUR RAHMAN ${ }^{1,2}$, ADOLFO DELGADO $^{1}$, \\ IBRAHIM HASSAN ${ }^{2}$, HAZEM NOUNOU ${ }^{2}$, RASHID HASSAN ${ }^{1} \&$ MOHAMED NOUNOU $^{2}$ \\ ${ }^{1}$ Texas A\&M University, USA \\ ${ }^{2}$ Texas A\&M University at Qatar, Qatar
}

\begin{abstract}
In the present study, the computational fluid dynamics (CFD) simulations of pinhole leaks (1.27$3.3 \mathrm{~mm})$ in a low-pressure, up to 2.5 bars, air pipeline which has $16 \mathrm{~mm}(0.62$ inch) inner diameter has been performed by using a 3D transient DES (detachable eddy simulation) model of a commercial CFD code, ANSYS Fluent R3. Also, a laboratory-scale experimental setup is established with a $5 \mathrm{~m}$ long pipe with inner diameter (ID) $=16 \mathrm{~mm}$. In steady operational stages, mass balance method is used to calculate the leakage mass flow rate in the experimental setup. In addition, pressure point analysis (PPA) with two dynamic and one differential pressure gauges is used to detect chronic/small leaks at transient stages. This method is cost effective and easy to maintain compared to expensive acoustic leak detection systems. The numerical results were validated against the experimental data. The simulations values of leakage mass flow rate are slightly higher $(\sim 10 \%)$ than the experiments but overall the simulation results are in good agreement with experiment. The proposed model simulates the flow leakage, pressure distribution and velocity profile around the defined size of the leakage. Transient simulation is performed to use power spectral density (PSD) and Fast Fourier transformation (FFT) of the acoustic pressure variation to predict acoustic oscillations and turbulent behavior of the flow field around the leakage location. These results could help advance current understandings of several leak detection systems that will reduce the false alarms of the leakage monitoring systems.
\end{abstract}

Keywords: CFD simulation, chronic leak detection, gas pipeline leakage, dynamic pressure wave monitoring.

\section{INTRODUCTION}

Pipelines have been used to transport water, fossil fuels, gases and chemicals, which are crucial for modern society, over millions of miles all around the world. Especially, oil and gas producer countries' (USA, Russia, UAE, Canada, Qatar, etc.) pipelines are vital link connecting reservoirs which are far away from main land to refineries, plants and consumers in the home/exported country. There are several ways to transfer petroleum products rather than pipeline, for instance rail or truck on land and oil tanker at off-shore, but using pipeline is more economical when you need to transport high volume of product over long distance.

The accidental release or admission of fluid through a hole is characterized as leak. There are several reasons of the leakage: bad workmanship, corrosion, excess fluid pressure change, cracks/defects in the pipeline, lack of maintenance and natural disasters.

Chronic leak detection is an important concern as they have the potential to be a significant contributor of green-house gases (GHGs) if they got undetected for extended periods of time [1]. Early and accurate detection is essential to minimize pipeline fracture propagation, continuous chronic leaks, and possible safety-related incidents.

Most industries collect abundant measurements from a variety of sensors monitoring different process variables, making it easy to draw relationships between different physical properties in order to carry out efficient fault detection, i.e., anomaly (or leak) detection [2]. Unfortunately, for subsea pipelines experiencing harsh conditions a limited number of 
sensors can be installed, due to installation and maintenance costs. Therefore, due to the lack of measurements from a multitude of different sensors, available sensor measurements need to be analyzed efficiently in order to carry out leak detection.

Ben-Mansour [3] performed 3D steady and transient turbulent CFD simulations for small leaks (below $1 \mathrm{l} / \mathrm{min}$ ) in water pipelines. The results indicate clear influence of the leak in the pressure gradient. Also, there is a significant change at the magnitude of the acoustic signal in presence of the leak. Moreover, Ben-Mansour [4] developed a CFD model that shows axial flow acceleration in the flow mid-plane of the pipeline that indicates clear gradient jump which can be used as leak detection method.

Liu [5] proposed a wavelet transform (WT) method by using quadrupole and dipole sonic sources. However, the time difference (TD) error were large due to fact the leakage time was not clear. Liu [6] studied an improved dynamic pressure waves method that localization of the leak in natural gas pipeline. We have performed numerical simulations and experiments for single phase flow [7]-[9], gas/liquid flow [10]-[14], solid/liquid [15], gas/liquid/solid flow [16], [17]. We have also previously conducted a critical literature review on onshore/offshore leak detection and single phase (crude oil and natural gas) leak detection computational fluid dynamics modeling [18]. In this study, we have applied the wavelet transform method on the dataset that was obtained from our computational fluid dynamics modelling. We have found that wavelet transform method is very effective tool in identifying the leak detection and localization.

\section{EXPERIMENTAL SETUP OF PINHOLE LEAK DETECTION FACILITY}

A low-pressure pipeline gas(air) leak detection setup is designed and established by our group. The pressure drop and leak flow rate are measured across a length of 1-meter pipe section (distance between $\mathrm{P} 1$ and $\mathrm{P} 2$ in Fig. 1). The total length of the setup is 4 meters straight stainless-steel pipe of 0.75 -inch outer diameter, 0.62 -inch inner diameter. P\&ID diagram of the single-phase leak detection test rig is shown in Fig. 1. The test rig is mounted on the top of lab bench shelves. The main air supply is connected to the university's air supply domain and provide air pressure up to 3.5 bars. There are two

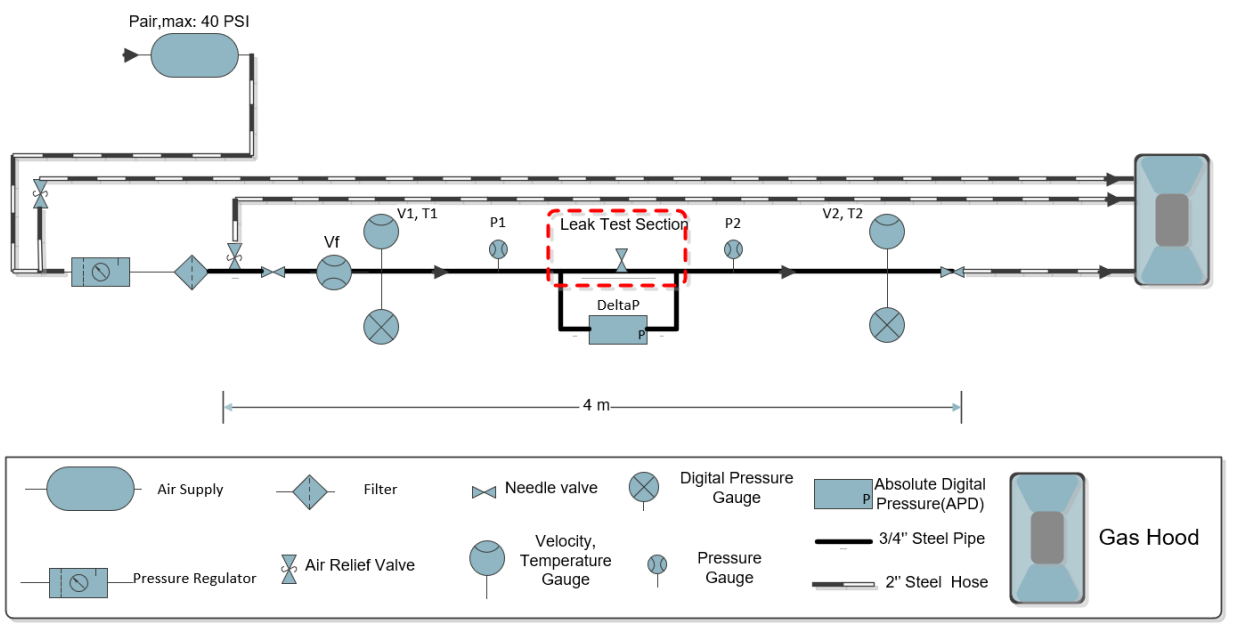

Figure 1: P\&ID of gas pipeline leak detection setup, the main instruments in the flow loop includes needle valve, solenoid valve, dynamic and differential pressure gauges. 
pressure relief valves set to 4 bars pressure to maintain the safety of the main pipeline. Furthermore, pressure regulator and air filter are mounted at the beginning of the loop to provide dry and clean air to the system. The leak flow rate is controlled by various size of solid-stream spray air nozzles which are controlled by on/off solenoid valve. The diameter of the spray nozzles are $0.05^{\prime \prime}(1.27 \mathrm{~mm}), 0.07^{\prime \prime}(1.778 \mathrm{~mm}), 0.09^{\prime \prime}(2.286 \mathrm{~mm})$, $0.1^{\prime \prime}(2.54 \mathrm{~mm})$, and $0.13^{\prime \prime}(3.302 \mathrm{~mm})$.

Data acquired by sensor with a constant pressure with no leak condition, then open the solenoid valve to create leakage. The spray nozzle can be changed with a different nozzle size at the end of data collection. The main instruments are used in this flow loop are: ESIdynamic pressure transducer (UPS-HSR-B02P5-N), Omega-flow and temperature sensor (FMA1003) and Omega-differential pressure sensor (PXM409-070HDWUUSBH).

\section{TRANSIENT CFD SIMULATIONS AND FFT ANALYSIS}

\subsection{Mathematical model of leak simulation}

\subsubsection{Mass conservation}

The equation of continuity (mass conservation) for transient flow can be written as eqn (1)

$$
\frac{\partial \rho}{\partial t}+\nabla \cdot(\rho \vec{v})=0
$$

\subsubsection{Momentum conservation}

A single set of momentum equation is solved throughout the computational domain, and the resulting velocity field is shared by the volume fractures of fluids. The momentum eqn (2), depends on the phases' volume fractures through the density and viscosity properties.

$$
\frac{\partial}{\partial t}(\rho \vec{v})+\nabla \cdot(\rho \vec{v} \vec{v})=-\nabla \mathrm{p}+\nabla \cdot\left[\mu\left(\nabla \vec{v}+\nabla \vec{v}^{T}\right)\right]+\rho \vec{g}+\vec{F}
$$

\subsubsection{Turbulence model}

The DDES (Delayed Detached Eddy Simulation) is applied to simulation, in order to study the transient turbulent behavior of the flow field inside the pipeline at single phase flow conditions.

In the DES model, which is a hybrid turbulence model, the unsteady RANS (Reynoldsaveraged Navier-Stokes) models are applied in the boundary layer while LES (Large Eddy Simulation) treatment is employed to the separated regions. The main advantage of DES over LES, DES model has been designed to address high Re number wall bounded flows, where it requires a smaller number of nodes. This model cost less computational time with its simplicity, respect to LES. However, the danger of grid-induced separation (GIS) where the flow separation depends on the critical value of $h_{\max } / \delta$ where $h_{\max }$ is the max cell edge length and $\delta$ is the local boundary layer thickness, not the physics of the flow [19]. Therefore, DDES shielding function is introduced [20], [21]. The DDES shielding function aims to preserve the eddy viscosity from degradation up to $h_{\max } / \delta=0.1$. The empirical delay function is presented in eqn (3)

$$
f_{d}=1-\tanh \left[\left(C_{d 1} r_{d}\right)^{C_{d 2}}\right]
$$

where $C_{d 1}, C_{d 2}$ are 20, 3 respectively, and $r_{d}$ shows in eqn (4) 


$$
r_{d}=\frac{v_{t}+v}{\kappa^{2} d_{w}^{2} \sqrt{0.5\left(S^{2}+\Omega^{2}\right)}}
$$

where

$v_{t}:$ eddy viscosity

$v$ : molecular viscosity

$S:$ strain rate

$\Omega$ : vorticity tensor

$\kappa$ : von Karman constant $(0.41)$

$d_{w}$ : distance to the wall

\subsection{Solution procedure and mesh quality}

A 3D turbulent flow simulation is conducted within the fluid domain of a pipe diameter $\mathrm{D}=$ $0.016 \mathrm{~m}$ and length of $\mathrm{L}=2 \mathrm{~m}$. The location of leak is at the center point of the mid-top section of the pipeline, shown in Fig. 2. The hole has a rectangular shape and to get a better resolution 10 cells per gap is defined. PISO (pressure implicit with splitting of operation) algorithm is used for pressure-velocity coupling scheme controls, because PISO may provide faster solution time at transient simulations for small time step sizes [22]. Table 1 indicated the details of boundary conditions and physical models.

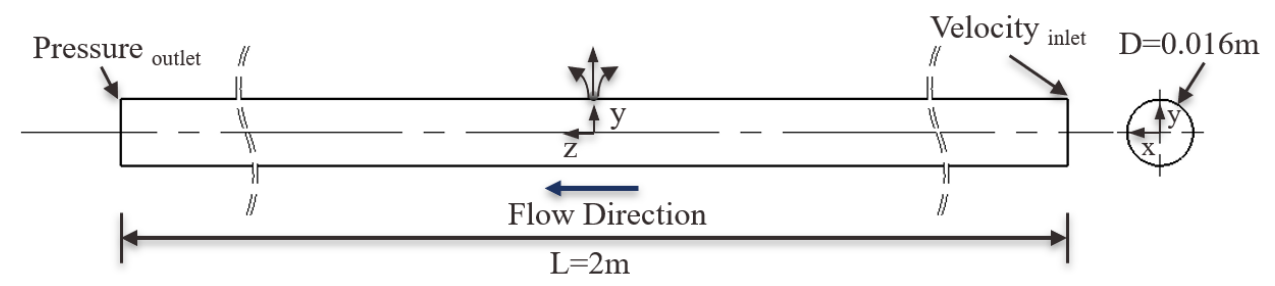

Figure 2: Geometrical design of the leak detection simulation's model (Leak center at, $\mathrm{x}=0, \mathrm{y}=\mathrm{D} / 2$ and $\mathrm{z}=0)$.

Table 1: Details of boundary conditions and physical models.

\begin{tabular}{|l|l|}
\hline Solution type & Transient-state (time-step: 0.001 s) \\
\hline Solver type & Pressure-based \\
\hline Fluid & $\begin{array}{l}\text { Air (real-gas (peng-robertson)) } \\
\text { Methane (real-gas (peng-robertson)) }\end{array}$ \\
\hline Inlet boundary conditions & Velocity inlet \\
\hline Outlet boundary conditions & Pressure outlet \\
\hline Turbulence model & DDES \\
\hline Acoustic model & FW-H equation \\
\hline
\end{tabular}

To ensure number of cells is not affect the solution independency, the mesh independence study is performed. Five meshes were designed and used with the boundary conditions of pressure outlet 78,000 Pascal, velocity inlet as $4.2 \mathrm{~m} / \mathrm{s}$ (Fig. 3). All meshes 
are maintained the lowest requirement of the acceptable mesh quality (minimum orthogonal quality $>0.01$ and maximum aspect ratio $<40$ for ANSYS Fluent). Due to fact we are using the supercomputer in TAMUQ and there is no cost constraints in this case, we decide to use 913 thousand polyhedral cells mesh model for our simulations to get a better accuracy and the resolution.

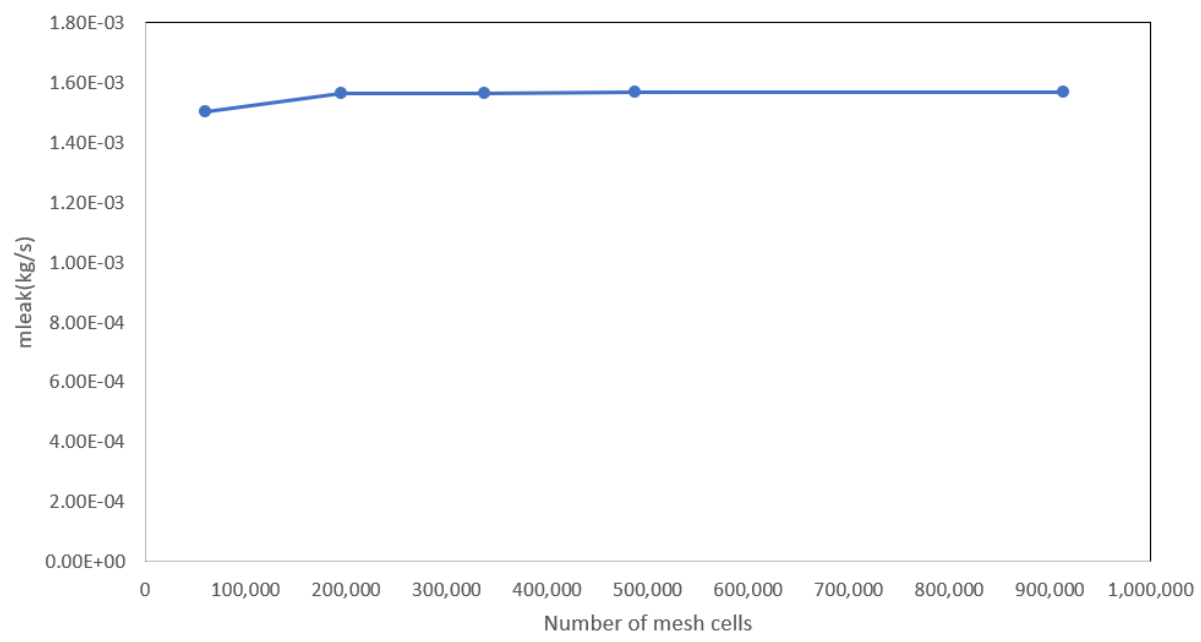

Figure 3: Mass leak flow rate versus number of cells.

\subsection{Boundary conditions}

The domain is named as velocity inlet, pressure outlet, leak pressure outlet and wall. The pipe inlet velocity and the pressure outlet values are prescribed from the experimental data set (Table 2). At the leak location, pressure outlet which is equal to the atmospheric condition is defined as boundary condition. Various leak sized (1.27, 1.788 and $3.302 \mathrm{~mm})$ are also defined at simulations.

Table 2: Test cases and the conditions are measured from the experimental setup and used as boundary conditions in the simulations.

\begin{tabular}{|c|c|c|c|c|c|}
\hline Case \# & $\begin{array}{c}\text { Inlet velocity } \\
(\mathrm{m} / \mathrm{s})\end{array}$ & $\begin{array}{c}\text { Inlet } \\
\text { temperature } \\
\left({ }^{\circ} \mathrm{C}\right)\end{array}$ & $\begin{array}{c}\text { Outlet } \\
\text { pressure }(\text { bar })\end{array}$ & $\begin{array}{c}\text { Outlet } \\
\text { temperature } \\
\left({ }^{\circ} \mathrm{C}\right)\end{array}$ & $\begin{array}{c}\text { Leak size } \\
(\mathrm{mm})\end{array}$ \\
\hline 1 & 37.56 & 22.5 & 2.07 & 24.1 & 1.27 \\
\hline 2 & 42.45 & 22.6 & 0.64 & 24.3 & 3.302 \\
\hline 3 & 42.3 & 22.2 & 0.77 & 23.08 & 1.788 \\
\hline 4 & 42.15 & 22.3 & 1.17 & 23.9 & 1.788 \\
\hline
\end{tabular}

The numerical leakage flow rate calculations are validated with experimental results for air cases and later on, same model is modified by the methane within the simulation to perform industrial conditions. 


\subsection{Model validation}

The simulation was carried out with different working pressure range between 0.2-2.5 bars and was validated with the experimental data. Fig. 4 shows the summary of the experimental and prediction. The simulations values of leakage mass flow rate are slightly higher $(\sim 10 \%)$ than the experiments but overall the simulation results are in good agreement with experiment. As the pressure inside the pipeline increases, pressure differences at the leak surface increases as well and cause higher leak flow rates. Moreover, leak flow rate increases as leak size increases, due to fact pressure loss across the leak surface decreases.

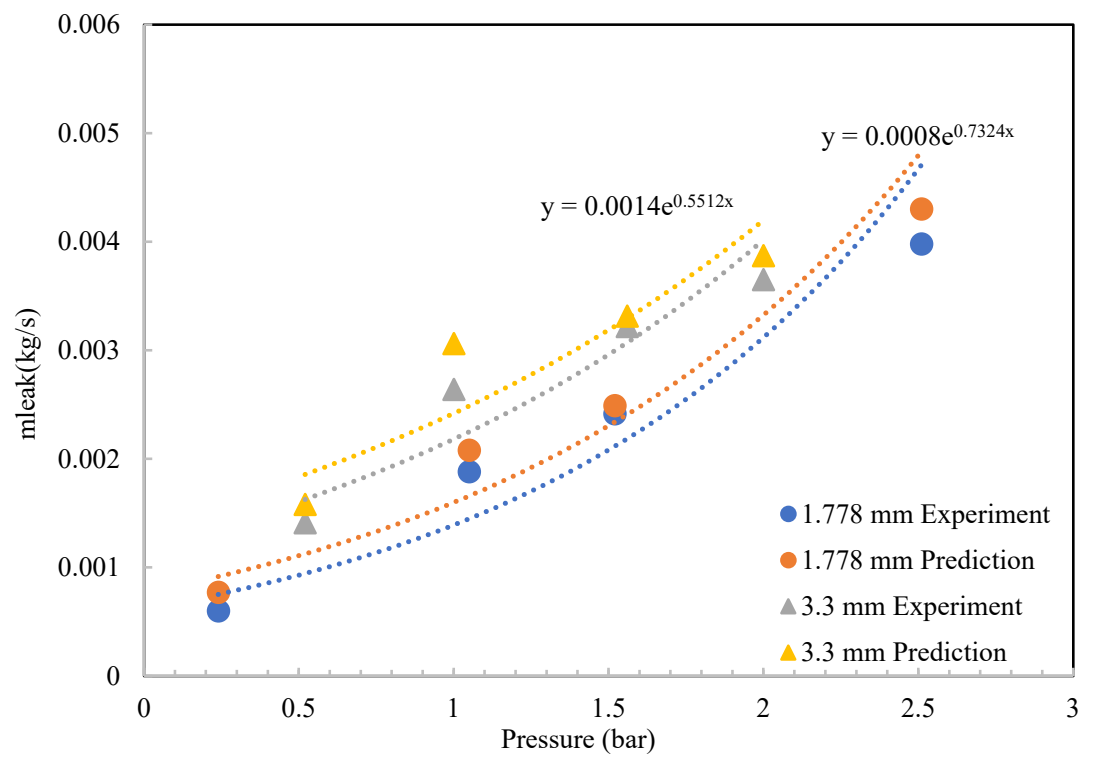

Figure 4: CFD prediction validation with experimental data on leak flow rate.

\subsection{Pressure and flow behaviors}

In this section, we study the pressure and flow behavior of air in the vicinity of a pinhole. Mainly case 3 is chosen to perform analysis at instantaneous time which is 10 seconds but all other cases have the similar trends. Fig. 5 illustrates the pressure contour around the $1.788 \mathrm{~mm}$ by $1.788 \mathrm{~mm}$ leak size. There is large pressure variation around the leak location, however the main pressure is dominating around the rest of the pipeline. The pressure is dropped to the atmospheric pressure gradually. This drop is limited with $1 \mathrm{~mm}$ region.

Fig. 6 indicates $\mathrm{x}$-vorticity contour field which shows the circulation region around the leak location. There are two local circulation regions, the maximum x-vorticity after the leak region and minimum one before the leak region.

Fig. 7 indicates the temperature variation around the vicinity. Due to the local cooling effect can be explained by the Joules-Thompson effect during gas decompression, 

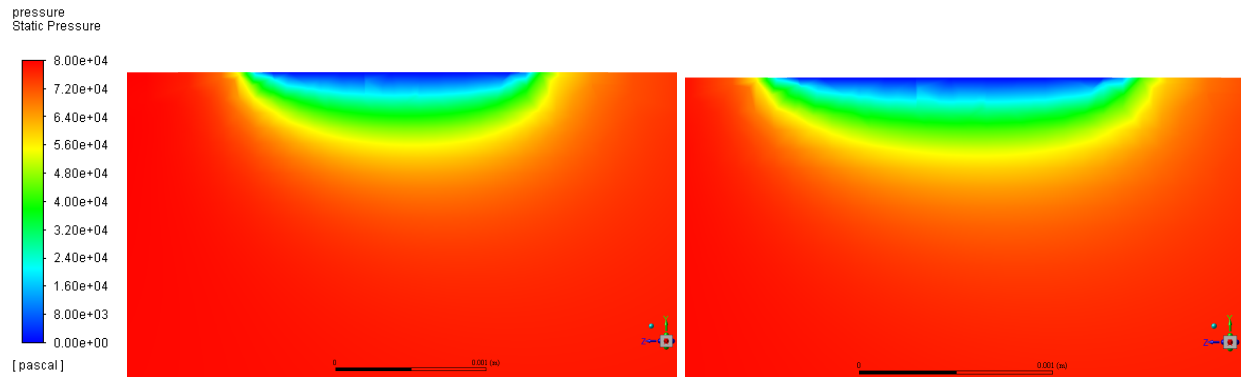

Figure 5: Pressure contours around the leak position, case 3, time $=10 \mathrm{~s}$ (left: air; right: methane).

X-Vorticity
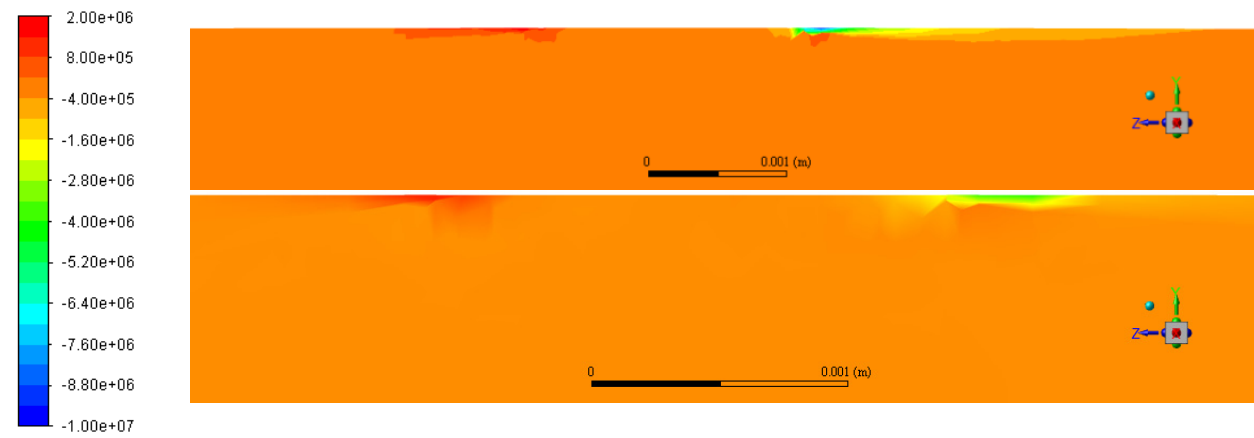

[1/s ]

Figure 6: $\quad \mathrm{x}$-vorticity contour field around the leak, case 3, time $=10 \mathrm{~s}$ (upper: air; lower: methane).
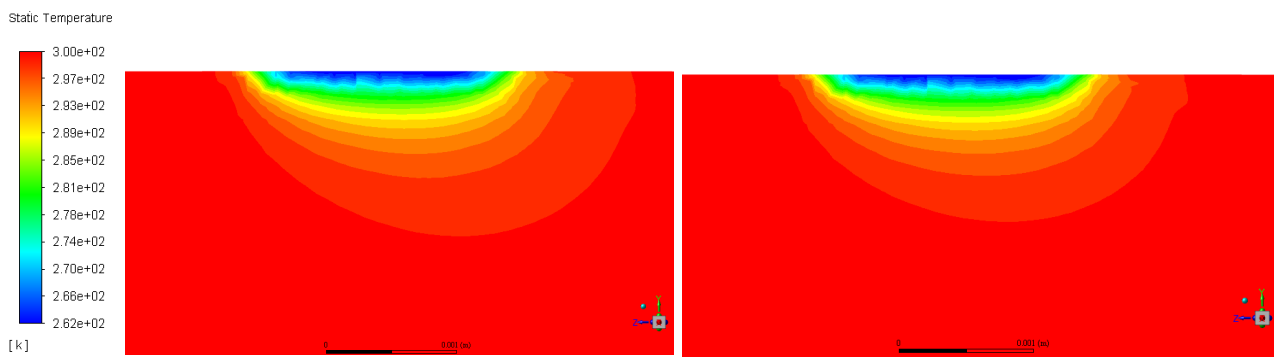

Figure 7: Temperature contours around the leak at the yz plane, time $=10 \mathrm{~s}$ (left: air; right: methane).

temperature drops around the leak orifice. Near the leak vicinity a strong vortex exists and results complex flow field around the leak. Due to this complex flow field around the leak small eddies dissipate, and the energy turns from kinetic energy to thermal energy, cause local warming effect near leakage region. 
Fig. 8 shows the static pressures distribution along the various line locations along the pipeline. Fig. 8(a) illustrates the sudden pressure drop at the leak direction along the line which is $1 \mathrm{~mm}$ below the leak point and midplane, respectively. The pressure drop is higher closer to the leak point and there is a slight pressure increases after the leak area. Fig. 8(b) indicates the difference between the case with and without leak for case 2. The reason of the kink at the pressure data, there is a circulation created due to leak region. After the leak region, velocity of the fluid decreases and local pressure is increased, suddenly.
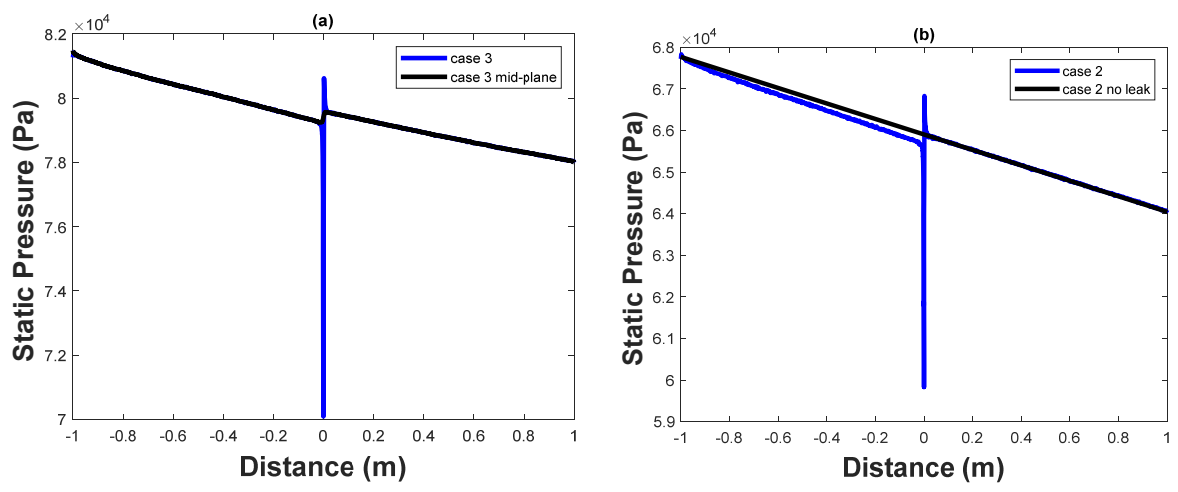

Figure 8: Pressure variation along the straight line, time $=10 \mathrm{~s}$. (a) $1 \mathrm{~mm}$ and $2 \mathrm{~mm}$ below the leak for case 3; and (b) $1 \mathrm{~mm}$ below the leak and no leak conditions for case 2 .

\subsection{FFT analysis}

The Fast Fourier Transform (FFT) and power spectral density (PSD) analysis are performing on the pressure signal to understand the transient turbulent behavior of the air flow field. In this study, Delayed Detached Eddy Simulation (DES) is conducted due to fact it is less expensive than the Large Eddy Simulation (LES), but still predict flow and turbulence distribution well around the leak location. Pressure fluctuations are monitored at several receiver locations.

In order to distinguish the leakage phenomenon, Fig. 9 illustrates FFT analysis of the pressure signal at prementioned receiver locations with and without leakage for the case 3 . Fig. 9(a) and 9(b) demonstrate the high amplitude frequency at $31 \mathrm{~Hz}$ with the PSD value is increased from 1,437 for no leak case to 12,610 for the case with leakage on y direction. The similar trend occurs on receivers at z-direction (Fig. 9(c) and 9(d)). The high amount of PSD magnitude is increased due to fact of the sonic sources which are generated when the leakage occurs. As discussed on the previous chapter, fluid turbulence around the leak area where gas jets out from the hole causes the sonic waves. Fig. 10(a) and 10(b) indicates the PSD value is increased from 1,283 for no leak case to 2,460 for the case with leakage on y direction. The similar trend can be monitored in Fig. 10(c) and 10(d). Moreover, the peak value, $31 \mathrm{~Hz}$, shows the main energy of the acoustic pressure at low frequency. Due to fact that low frequency can transfer long distance, it is easier to detect this signal within the short time. 

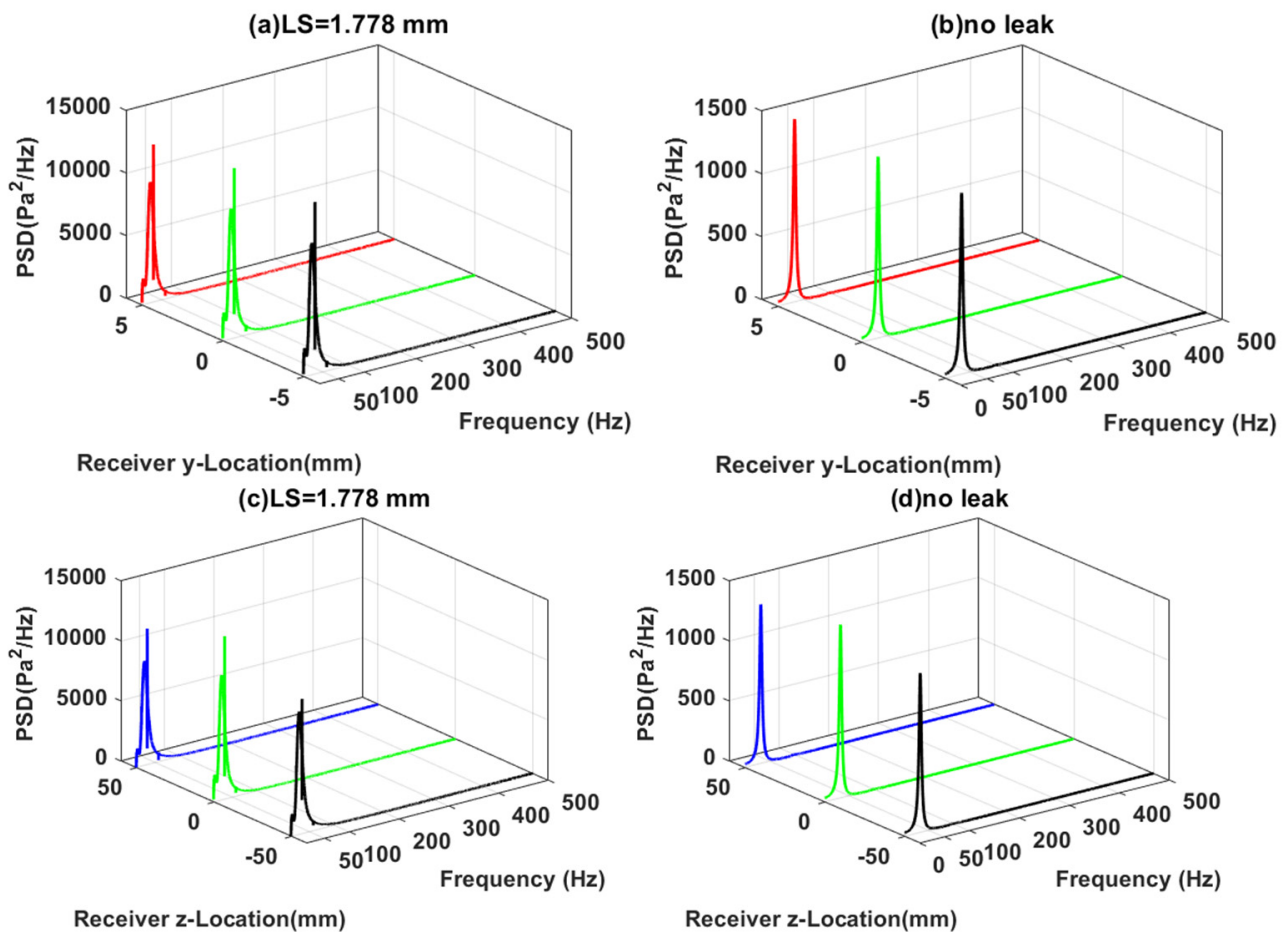

Figure 9: FFT of pressure signal at various receiver locations for case of leak (left), and with no leak (right)-case 3.

\section{CONCLUSION}

The main objective of this study is to determine the observable trends of pinhole leaks in gas pipelines. Experimental setup is established to implement of pressure point analysis PPA for leak detection. Also, three-dimensional, transient CFD turbulent flow simulations are performed to investigate the unsteady behaviors of the fluid domain in the near region of the leak. We can summarize the conclusions as follows:

1. Leak mass flow rate is calculated from the mass balance method at the steady conditions by experimental setup. For low gas pressure application, it is an accurate method to use.

2. Pressure point analysis (PPA) method is used to monitor dynamic and differential pressure at before and after the leak point to compare the previous pressure measurements. This method is cost effective and easy to maintain.

3. Gas leak causes high peak of the acoustic pressure signal for the range of $31 \mathrm{~Hz}$ frequency. Acoustic energy of pressures causes high peak on the low frequency, due to fact that low frequency can transfer long distance, it is easier to detect this signal within the short time.

4. Acoustic energy analysis on different positions shows there is a correlation between the signal's magnitude and leak location. More simulations are needed to develop a precise model to foresee effects and outcome of future accidents caused by the hazardous material from the pipeline leak. 

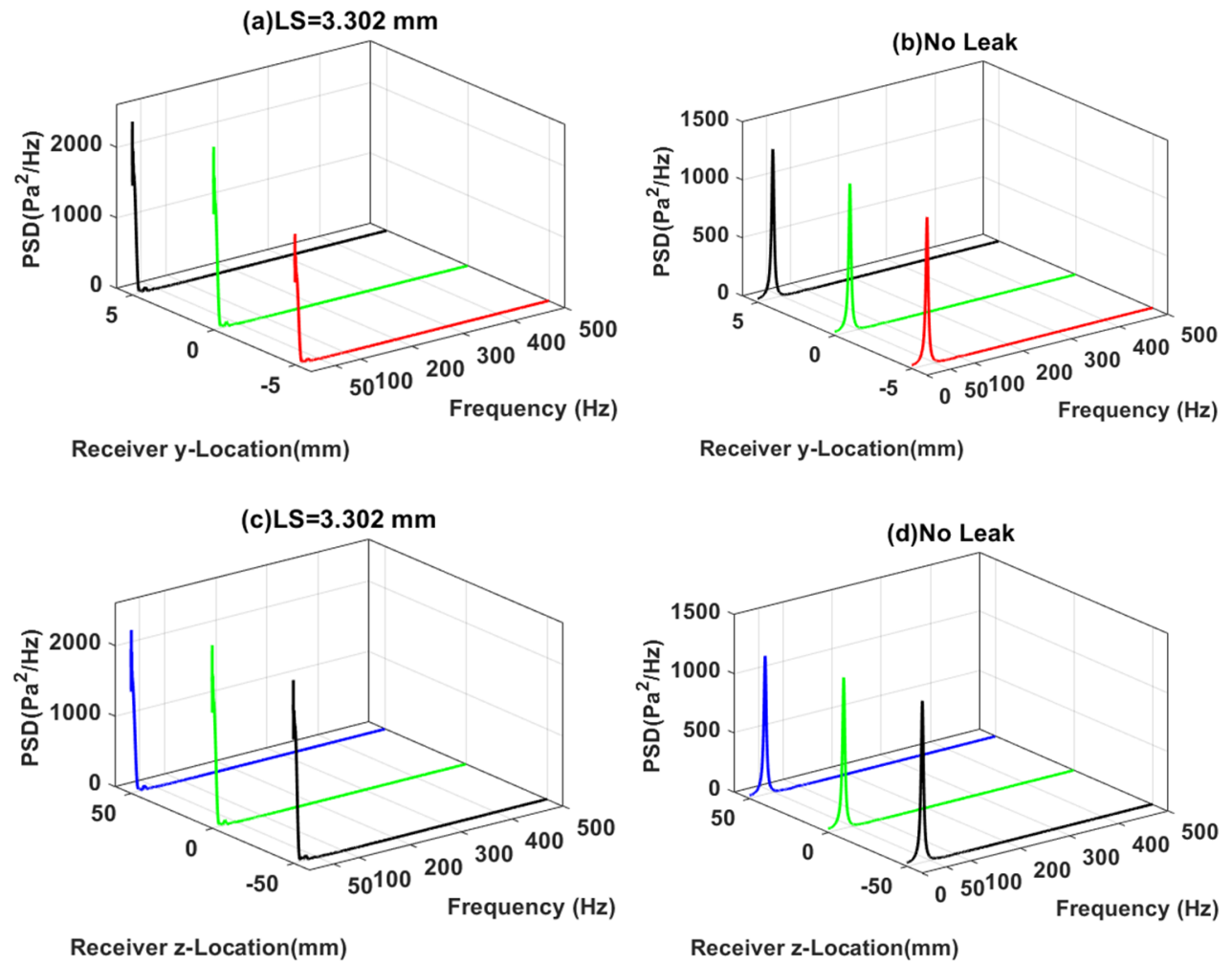

Figure 10: FFT of pressure signal at various receiver locations for case of leak (left), and with no leak (right)-case 2.

All aforementioned methods are used for detecting leaks in gas pipeline systems in offshore application. Future studies will focus on the accurately localization of the leak by using the above methods.

\section{ACKNOWLEDGEMENTS}

The HPC (High Performance Computing) resources and services used in this work were provided by the Research Computing group in Texas A\&M University at Qatar. Research Computing is funded by the Qatar Foundation for Education, Science and Community Development. This publication was made possible by the Responsive Research Seed Grants (RRSG) funding provided by Texas A\&M University at Qatar.

\section{REFERENCES}

[1] Behari, N., Sheriff, M.Z., Rahman, M.A., Nounou, M., Hassan, I. \& Nounou, H., Chronic leak detection for single and multiphase flow: A critical review on onshore and offshore subsea and Arctic conditions. J. Nat. Gas Sci. Eng., 81, Elsevier B.V., 01 Sep. 2020. DOI: 10.1016/j.jngse.2020.103460.

[2] Joliffe, I.T., Principal Component Analysis, 2nd edn, Springer-Verlag: New York, 2002. 
[3] Ben-Mansour, R., Habib, M.A., Khalifa, A., Youcef-Toumi, K. \& Chatzigeorgiou, D., Computational fluid dynamic simulation of small leaks in water pipelines for direct leak pressure transduction. Comput. Fluids, 57, pp. 110-123, 2012.

DOI: 10.1016/j.compfluid.2011.12.016.

[4] Ben-Mansour, R., Suare, K.A. \& Youcef-Toumi, K., Determination of important flow characteristics for leak detection in water pipelines-networks. 9th International Conference on Heat Transfer, Fluid Mechanics and Thermodynamics, Malta, 2012.

[5] Liu, C., Li, Y., Meng, L., Wang, W. \& Zhang, F., Study on leak-acoustics generation mechanism for natural gas pipelines. J. Loss Prev. Process Ind., 32, pp. 174-181, 2014. DOI: 10.1016/j.jlp.2014.08.010.

[6] Liu, C., Wang, Y., Li, Y. \& Xu, M., Experimental study on new leak location methods for natural gas pipelines based on dynamic pressure waves. J. Nat. Gas Sci. Eng., 54(Mar.), pp. 83-91, 2018. DOI: 10.1016/j.jngse.2018.03.023.

[7] Xiong, X., Rahman, M.A. \& Zhang, Y., RANS based computational fluid dynamics simulation of fully developed turbulent Newtonian flow in concentric annuli. $J$. Fluids Eng. Trans. ASME, 138(9), pp. 1-9, 2016. DOI: 10.1115/1.4033314.

[8] Amin, A., Imtiaz, S., Rahman, A. \& Khan, F., Nonlinear model predictive control of a Hammerstein Weiner model based experimental managed pressure drilling setup. ISA Trans., 88, pp. 225-232, 2019. DOI: 10.1016/j.isatra.2018.12.008.

[9] Rahman, M.A., Mustafiz, S., Biazar, J., Koksal, M. \& Islam, M.R., Investigation of a novel perforation technique in petroleum wells-perforation by drilling. J. Franklin Inst., 344(5), pp. 777-789, 2007. DOI: 10.1016/j.jfranklin.2006.05.001.

[10] Rahman, M.A., Heidrick, T. \& Fleck, B.A., Characterizing the two-phase, air/liquid spray profile using a phase-doppler-particle-analyzer. IOP J. Phys. Conf. Ser., 147(Jan.), pp. 1-15, 2009.

[11] Rahman, M.A., Heidrick, T. \& Fleck, B.A., A critical review of two-phase gas-liquid industrial spray systems. Int. Rev. Mech. Eng., 3(1), pp. 110-125, 2009.

[12] Ahammad, M.J., Rahman, M.A., Zheng, L., Alam, J.M. \& Butt, S.D., Numerical investigation of two-phase fluid flow in a perforation tunnel. J. Nat. Gas Sci. Eng., 55(Nov.), 2017, pp. 606-611, 2018. DOI: 10.1016/j.jngse.2017.10.016.

[13] Sleiti, A.K., Takalkar, G., El-Naas, M.H., Hasan, A.R. \& Rahman, M.A., Early gas kick detection in vertical wells via transient multiphase flow modelling: A review. $J$. Nat. Gas Sci. Eng., 80(May), p. 103391, 2020. DOI: 10.1016/j.jngse.2020.103391.

[14] Manikonda, K., Hasan, A.R., Kaldirim, O., Schubert, J.J. \& Rahman, M.A., Understanding gas kick behavior in water and oil-based drilling fluids. SPE Kuwait Oil Gas Show Conference, 2019, KOGS 2019, 2019. DOI: 10.2118/198069-ms.

[15] Herath, D., Khan, F., Rathnayaka, S. \& Rahman, M.A., Probabilistic estimation of hydrate formation. J. Pet. Sci. Eng., 135, pp. 32-38, 2015.

DOI: 10.1016/j.petrol.2015.08.007.

[16] Qureshi, M.F., Ali, M., Rahman, M.A., Hassan, I., Rasul, G. \& Hassan, R., Experimental investigation of multi-phase flow in an annulus using electric resistance tomography. SPE Kuwait Oil Gas Show Conference, 2019, KOGS 2019, (Mar.), 2018, pp. 1947-1956, 2019. DOI: 10.2118/198011-ms.

[17] Zahid, A.A., ur Rehman, S.R., Rushd, S., Hasan, A. \& Rahman, M.A., Experimental investigation of multiphase flow behavior in drilling annuli using high speed visualization technique. Front. Energy, 14(3), pp. 635-643, 2020.

DOI: 10.1007/s11708-018-0582-y. 
[18] Jujuly, M., Thodi, P., Rahman, A. \& Khan, F., Computational fluid dynamics modeling of subsea pipeline leaks in Arctic conditions. Arctic Technology Conference Offshore Technology Conference, St. John's, Newfoundland and Labrador, Canada, p. 19, 2016. DOI: 10.4043/27417-MS.

[19] Menter, F.R., Kuntz, M. \& Langtry, R., Ten years of industrial experience with the SST turbulence model turbulence heat and mass transfer. Cfd.Spbstu.Ru, 4(Jul.), 2014, pp. 625-632, 2003.

[20] Gritskevich, M.S., Garbaruk, A.V., Schütze, J. \& Menter, F.R., Development of DDES and IDDES formulations for the k- $\omega$ shear stress transport model. Flow. Turbul. Combust., 88(3), pp. 431-449, 2012. DOI: 10.1007/s10494-011-9378-4.

[21] Spalart, P.R., Deck, S., Shur, M.L., Squires, K.D., Strelets, M.K. \& Travin, A., A new version of detached-eddy simulation, resistant to ambiguous grid densities. Theor. Comput. Fluid Dyn., 20(3), pp. 181-195, 2006. DOI: $10.1007 / \mathrm{s} 00162-006-0015-0$.

[22] Versteeg, H.K. \& Malalasekera, W. (eds), An Introduction to Computational Fluid Dynamics: The Finite Volume Method, 2nd edn, Pearson Education Ltd., 2007. 